\title{
Re-Classification of Roofs in Multi Storey Design Education and Application: A Pedagogic Approach
}

\author{
Botchway EA* and Aba Essanowa Afful* \\ Kwame Nkrumah University, Ghana
}

Received: 眥 February 16, 2018; Published: 畫 February 23, 2018

*Corresponding author: Botchway EA, Aba Essanowa Afful, Kwame Nkrumah University of Science and Technology, Ashanti Region, Kumasi, Ghana, Email: edbotchway@gmail.com; abaafful@yahoo.com

\begin{abstract}
Pedagogy comprises of all the actions one takes to incite learning in others. They are the instructional techniques and strategies that would allow learning to take place. It is the interactional communication between a learner and a teacher that is influenced by the social, cultural and to an extent the political views of both the teacher (educator) and the child or (the learner) (Lynn,2017). The Ghanaian construction industry has over the years aimed at improving the knowledge base of students and workers alike. Towards this a system of teaching and learning has been adopted and has been maintained as the traditional method. However, in as much as teaching has evolved all around the world, our system of teaching, training and development has not gone through so drastic a change as to meet international standards of education. There is the need to inculcate a paradigm shift in the system of teaching. In the construction of Multi-storey buildings, there are varying types of roofs that are used and each of them are associated with their very own functions, structural compositions and their interaction with the storey building itself. Roofs and their construction has evolved over time with the change in technology and the need for more functionality and the complexity in designs however their classification for teaching purposes has not evolved to suit these changes. The purpose of this paper is to propose an ideal method of teaching roofing types and classification that can be adopted for use within the universal, tertiary teaching and learning setting. In doing this we re-classify roofs of multi-storey structures based on their varying functions, construction components, technology and complexity of design to improve the learning experience of students within the construction industry. They are Aesthetic roofs, Utility roofs, Service roofs, Drainage functional roofs and Structure stabilization roofs. In view of this, case studies of various internationally acknowledged multi-storey structures were analyzed to obtain the varying proposed classes of roofs. As early on stated, there is the need for a paradigm shift in the educational system and for that to hold, there is the need for educators to improve the pedagogic approach.
\end{abstract}

Keywords: Pedagogy; Roof classifications; Multi-storey structure roofs

\section{Introduction}

The teaching process is a performance event as well as a performative event. By this statement, teaching is assessed based on the performance of the student as well as how well the teacher performs in the classroom. The ability to impart knowledge and the extent to which it is absorbed and utilized. Alexander et al. [1]. This is the basis on which the educational standards are set. In the classroom there is the need to device varying strategies during the learning process. However, innovative teaching in the classroom is made handicap by the introduction of strict curriculum based teaching style. The Educational curriculum does not allow for much variations in the learning process. In order to affect change in the teaching aspect of education, there is the need to put to reform the curriculum and syllabus of the educational institution.

In the country, the Ghana Educational Service (GES) in collaboration with the Ministry of Education is responsible for putting together a syllabus and curriculum to be followed in the Ghanaian educational system. With respect to this, the syllabus has undergone very little changes in accordance with the ever-changing 
world we see around us. New discoveries have been made, new technologies have been introduced and the old ways of thinking and doing things have taken a completely different turn. It is sad however to note that the Ghanaian educational system has not been able to adapt these changes into the educational system hence churning out students with archaic knowledge on the happenings of the various industries they find themselves in.

With specific reference to the construction industry, there have been massive improvements to the methods of construction, the technologies used in the industry, the concepts behind the design of building components as well as the complexity and the size of building projects. There is the need to keep ourselves upto-date with these happenings so as to place the products of our educational system at par with international standards. Teaching methods as well as the topics taught are to be put under review to remove the chaff, simplify the complex and expound on the current.

To be able to explicitly teach concepts in Multi-storey roofing design, there is the need to properly identify and classify multistorey roofing systems. In discussing these buildings, we are able to assess their functions and roofing requirements. These requirements and functionality would aid in adequately classifying roof types. Roofs have generally been classified based majorly on the degree of slope, material composition and resistance to fire. This has to a very broad extent been used in both low-rise and high rise buildings.

With the ever changing world in which we live in, roofs are not just for the purposes of providing shelter and drainage. Their material compositions, construction methods, and design have all evolved over the years and this now has a bearing on the design concept that are currently in use. There is the need for the construction industry to move from the old methods of classification to adopt and accommodate these changes both within the classrooms and in the field of application. This paper attempts to identify the various requirements of roofs in multi-storey buildings and hence properly classify their roofs accordingly for pedagogic teaching and learning as well as in its application within the construction industry.

\section{Literature Review}

\section{What is a Multi-storey Building?}

In attempting to identify the roof classifications for multi-storey structures we need to define a multi-storey structure. A multistorey building is any structure with multiple floors and typically a vertical circulation area. That is to say stairs, lifts, etc. According to Design Buildings Ltd, multi-storey buildings range from two (2) to one hundred and fifty (150) storey design. They can be classified into:
a. Low-rise
b. Mid-rise
c. High-rise

\section{d. Skyscrapers}

e. Supertall

f. Mega tall Structures (Design Buildings Ltd., [2])

These various classes of multi-storey structures demand varying types of roofs according to the functionality required of the roofs. What we see in the pedagogy of roofs is the archaic concept that roofs are classified according to their slopes. Presently, the classes and types of roofs taught to students in classrooms need to be reviewed. Students at the tertiary level and above need to be abreast with the current trend of technology and the evolution of construction and hence the need to rethink the classification of roofs as taught in classrooms.

\section{Present Classification of Roofs}

Presently, there are varying methods that are used to classify roofs. Some roofs are classified based on their slopes, others are classified based on the material for covering and the shape of the roof. None of these classifications take into consideration the type of building or the alternative use of the roof apart from the common traditional uses. Presently, the most common classification of roofs is of two broad forms. Namely; Flat roofs and Pitched roofs.

Barry [3] defines a flat roof as a timber, metal or concrete platform normally horizontal or inclined at an angle of up to 5o to the horizontal. Barry [3]. Flat roofs have been around for centuries. In the early 19 th Century flat roofs were commonly used due to building Acts in place at the time regulating the heights of buildings. With flat roofs, the highest number of floors within the building height regulation could be constructed. At the time, wood was the major roof membrane material. Flat roofs used less wood membranes making the roof lighter and consequently cheaper to construct. Over the years, the emergence of roof top gardens added value to the construction of flat roofs. These gardens have evolved to become known as green roofs though at the core they are flat roofs. (Urbanik \&Tomaszewicz, [4])

The construction of flat roofs need to meet three basic functions; insulation, waterproofing and construction. The major problem encountered with flat roofs is found in the ponding of water which causes dampness and consequent variation in temperature within the building. Its construction is however relatively easier and as such less expensive (Chudley \& Greeno, [5]). In recent times, flat roofs have gone beyond the three basic functions that are required to be met and have become more sophisticated in functionality.

Pitched roofs or sloping roofs come in varying forms. They are more common to residential buildings. They can either be lowsloped or steep-sloped. In the construction of sloped roofs, there is the need to determine the requisite slope and the pitch. The slope has to do with the roofing of the house whereas the pitch has to do primarily with the construction of the roof. (Wells, [6]) A common form of sloping roofs is the pitched roofs. The term 
pitched is obtained from the concept of tent construction where there are several lengths of wood put together to meet at a central point. Comparatively, the flat roof is cheaper to construct due to the method of construction which involves joining triangular frames of sloping rafters, tied and trussed together with horizontal ceiling joists with a system of struts and ties (Barry [3]). However, sloping roofs offer more void for services and for storage. They are better suited for areas with heavy rainfall or snowfalls. This is because it enables run-off of rain and snow. Some types of sloped roofs include; the gable roof, the butterfly roof, mansard, gambrel, hip roof, etc. (Figure 1). It is therefore prudent that these roofs be made into classes of their own separate from the basic construction concept. These classifications would depict the design requirement, roofing materials and the construction techniques.

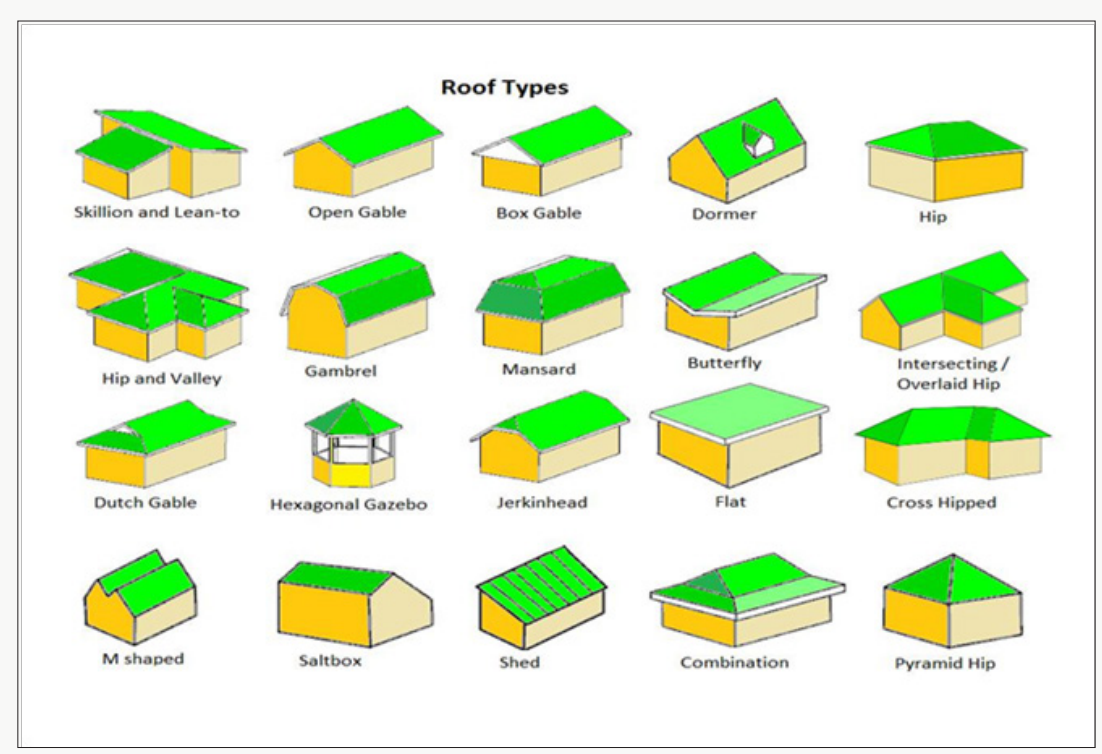

Figure 1: Source: Roof Cost Estimator, BigAl (2017).

Proposed Classification of Roofs in Multi-Storey Structures

\section{Aesthetic roofs}

These roofs are constructed majorly to portray the beauty and creativity of architects. In as much as they possess the strength and stability and are designed to meet critical functional requirements, these roofs have aesthetic and creativity at their core and as such beauty is not compromised. A typical example of such roofs is Glass roofs and green roofs. These roof are designed to be timeless and elegant.

The art science museum, Singapore: This museum is located in the iconic Marina Bay Sands in Singapore. Its roof is designed as an open lotus. It represents one of many buildings constructed in Singapore's drive towards boasting of ultra-modern architectural feats. (Singart [7]). This breath-catching building was designed by renowned architect and author, Moshe Safdie. In its design, the architect bore in mind an environmentally sensitive building. The lotus-shaped roof collects water and light for the museum's use. Additionally, each extended finger serves as a skylight that fills the upper galleries with daylight. The building utilizes an emerging form of air cooling technique known as "air stratification". This building was designed majorly with aesthetic purposes in mind. The main idea was to create a structure with an accompanying roof that catches the eye at whichever angle I is looked at. Additionally, features were put in place to make its roof eco-friendly and utilize the shape given by the architect to feed the building. Such a roof can only be placed under an aesthetic roof classification.

The Lotus temple: Located in New Delhi (India), this architectural feat designed by Iranian Architect; Furiburz Sabha, is shaped like a lotus in bloom. The structure is made of pure white marble and is the last of the seven major Bhai's Temples all around the world. It was opened in 1986. This structure is a typical example of the expressionist architecture in which structures were designed to differ greatly from its surroundings and stand out. With the elaborate design of this building, it cannot be placed under any of the traditional classifications of roofs. The tops of the structure points upward to depict the insides of the lotus flower. It would be impossible to place a lotus shaped roof under the traditional classifications currently being taught. The topmost part of the lotus looks closed but in actuality is fitted with a glass and steel roof that admits daylight to enhance the lightening within the structure and reduce energy costs. The structure is surrounded by pools to give a floating effect when viewed from the top of it. (Britannica, [8]). All in all, this structure was designed boundless by the traditional roof classes.

Sydney opera house: Acclaimed as an international architectural icon of the 20th century, this structure is famous for its timeless design. Designed by Jørn Utzon and opened by Queen Elizabeth in 1973, this structure has continuously stood the test of time in terms of design. The structure is inspired by sails of 
a boat and modified to become shell-like to suit the bay area on which it stood. The shells of the structure are made from concrete and are massive in size. The interior of the building was designed to hold the weight of this roof structure. Each shell was covered in ceramic tiles from Sweden and the entire structure took 11 years to complete. The nature and design of this roof does not follow the present classifications of roofs. It was designed to become a world architectural icon and it fulfilled this purpose. This design won the international competition from which it was chosen.

\section{Utility roofs}

Roofs of multi-storey buildings which incorporate utility services on them are in vogue. Roofs now have gardens, pools, parks, helipads, etc. Common among them are solar roofs and the green roofs. These roofs leave the traditional functions of providing shelter and rather offer scenery and relaxation at no cost of extra land use. It is especially useful in tightly packed cities with little land to spare. Here, the rooftops are converted into bars, restaurants, gardens, pools, parks, etc.

Green roofs and roof gardens: For thousands of years, Roof gardens have been used and have continued to evolve over the years and are now popularly referred to as green roofs. This roofing technology has been used for varying purposes. They are simply roofs that have been planted with specific vegetation. Initially, they used to be made from only flat roofs but now can be made on sloping roofs as well. A green roof system consists of layers that mimic natural processes and also protect the building and roof. The basic components are: a waterproof layer, root repellent membrane, filter cloth (to allow water to drain but prevent soil escaping), moisture blanket (to ensure enough water retention for plant life), drainage system (to drain excess water), soil substrate, seeds and plants. Living roofs can be designed to grow native plants that might otherwise become endangered. (Afful [9]). In some portions of the world, green roofs are used to cool temperatures in the homes of occupants. The vegetation which prevents the direct contact of the sun from reaching the houses are efficient in providing the adequate cooling effect needed. Green roofs range from a simple rooftop planting to a roofs complete with parks and trees. They are especially important in controlling greenhouse emissions, and provide comfort and relaxation when needed. (US. EPA, 2017). Some case studies are seen below.

Nanyang technological university: The School of Art, Design and Media located at the Nanyang Technological University in Singapore has a curving green roof structure, with an organic, vegetated form that blends nature and high-tech and symbolizes the creativity it houses. The open roofs serve as informal gathering spaces; insulate the building and harvest rainwater for landscaping irrigation. The glass façade reduces solar gain, while allows natural views of the surrounding foliage.

Kraiser center: This 28-storey magnificent structure spots a 3.5acre roof top garden. The Roof top garden is located on the 1,339 space rooftop garden. This rooftop garden design was inspired by the rooftop garden at Rockefeller Center in New York City. The owner of the building, industrialist Henry Kaiser hired Osmundson \& Staley to design a garden on top of the parking garage next to his company's headquarters. The garden opened in 1960 as the first "true" post-World War II rooftop garden in the U.S. This made it a historic site in the United States. (The Cultural Landscape Foundation [10])

\section{Roof parks}

Space within cities is limited and this has created the need for using roofs for alternative purposes one such being roof parks. Roof parks have become increasingly more popular. Office owners and property managers are looking for ways to provide a better and greener work environment for their employees. Creating a roof park means extra space, the possibility to relax, have meetings and have lunch while getting some fresh air. Hotels and restaurants are also increasingly making use of the unique possibilities roofs have to offer, like growing their own vegetables and herbs. (De Dakdokters [11]). This to an extent is a green roof with added facilities. Some multi-storey structures have taken roof parks to the extreme with the provision of bars, restaurants, pools, and cafés. Typical multistorey structures with roof parks are seen below.

Marina bay sands casino hotel: This famous casino hotel is known for its architectural elegance. Not only is it catchy at first sight but grand in its structural composition. The casino hotel has three building "legs" supporting a cantilever known as the Skypark. The three towers or legs stand individually until they unify at level 23. The SkyPark infamously called is the roof of this structure. It features an infinity pool, bars, restaurants, clubs and viewing decks. The Skypark is a cantilever longer than the Eiffel Tower and measures about 12,000 square meters in size. Famous for its Infinity Pool of 150meters, this roof certainly has more than shelter from the elements to offer (Marina Bay Sands [12]).

City beach bar: Frankfurt boasts of many rooftop bars referred to as the "Beach Clubs". City Beach however is located on the rooftop of a parking deck multi-storey building. As the name suggests, it is a beach brought into the heart of the city. It is a rooftop bar that incorporates features of the beach. With a breathtaking view of the city and beach sand to give the impression of an actual beach and two pools. This roof top bar or city beach makes any visitor forget that it is a converted roof. According to reviews, it is a swift conversion from the gray of the parking floors to the paradise of a roof beach. (Brevoord [13]).

\section{Rooftop helipads and heliports}

Helipads are common on the rooftops of hospitals although over the years, hotels and other industries have adopted them. They provide a faster means of transport and especially important where time is of the essence and the need to avoid the city traffic. In many other buildings, these helipads are useful in fire rescue. When a structure catches fire, occupants can easily assemble on the 
rooftops to be rescued. They are in this sense used as emergency rescue points or exits. In the use of rooftops as helipads however, certain design criteria must be met as well as city regulations to prevent the helicopters from causing a nuisance to surrounding buildings. It is well known that helicopters are noisy and as such, locating a helipad within the city would need to consider this factor. Additionally, the load that the roof would bear to accommodate the helicopter.

There are differences between a helipad, a heliport and a helistop. Generally, they are areas of land, water or structure used or intended to be used for the landing and takeoff of helicopters. A heliport is a more elaborate facility usually associated with helicopter fueling, maintenance hangars or passenger waiting areas. A helistop is a minimally designed heliport. With heliports, it need to be elaborate and complete to fully service helicopters and capable of holding helicopters for long periods while helistops are a smaller version of heliports without all the facilities required of heliports. This is what differentiates them. Helipads can be used interchangeably with helistops. (Gearson/ Overstreet Architects [14]).

A Helipad is not just a circle painted on a raised rooftop structure. It performs more function than just serving as a landing a takeoff site for helicopters. The size of the helipad depends upon the size of the largest helicopter or the size parameters (length, width and weight) of a combination of helicopters that may utilize the helipad (Gearson/ Overstreet Architects [14]).

A rooftop helipad requires additional fire prevention equipment such as one or two wet standpipes and a fuel water separator tank to be used in the event of a fuel spill to prevent the fuel from entering the sewer system. It is recommended that all helipads have fire extinguishers or a rooftop foam system. If a helipad is higher than 30 inches (0.762 meters) above the roof deck, a safety net for fall prevention is required. (Gearson/ Overstreet Architects [14]). All of these design and location criteria help in making the helipad more acceptable to its surroundings and a safer place to land. In order to make it fire proof, Helipads are not equipped with re-felling equipment and the touchdown surfaces are constructed with impervious and non-combustible materials (Walnut Creek Municipal Code [15]).

\section{Service roofs}

These roof spaces accommodate external services such as: storage tanks, air-condition outer units, Radio/TV masts etc., and these complement the total function of the building. Such roofs are designed to bear loads that come with the various service facilities. Some are designed with spaces to embed the services. The major consideration in such roofs is not its slope, or shape but the ability to accommodate the external services.

Solar Roofs: These roofs do not simply provide shelter from the elements. They additionally tap energy from the sun and convert it into energy for use within the buildings. With the increasing greenhouse emissions, one sustainable method for reducing this is the use of solar roofing to generate power. It is increasingly gaining grounds all over the world. In China for instance, Huang Ming a solar power researcher is at the forefront of pushing China to become a solar powered nation with his drive to make China and the world as a whole as sustainable in energy production and usage a possible.

Solar roofs are a cheaper and reliable solution to energy usage. The main resource is the sun which is available for absolutely no costs. The solar energy tapped can be converted into either thermal energy or electrical energy. In multi-story structures, where energy consumption is relatively higher, the use of solar energy absorbs a significant amount of costs that would have otherwise accrued were solar not used. In multi-storey structures, the high consumption requires a cheap source and efficient source of energy for dayto-day running of activities. The installation of roofing panels on rooftops makes good use of the roof cover space adequately while providing energy for the buildings consumption. Structures located in areas off the national grid can reliably fall on solar energy for power. Additionally, solar canopies are becoming increasingly common. Where they provide shade as well as generating solar energy on the roofs of buildings.

Rooftop storage tanks: Rooftop storage tanks are used in varying ways but majorly to store liquids but in some cases to store gases. These tanks are commonly used for water storage though as early stated can be used in the storage of other liquids and gases. In the construction of such tanks, the wind loads that will affect them are put into careful consideration as well as the loads that would be placed on the raised platform and subsequently the roofs.

In multi-storey structures, the one major concern is the provision of water to upper floors. This dilemma has been solved by the introduction of rooftop water storage facilities. These tanks are mounted on the roofs of the building. The roofs of such buildings are designed to provide a continuous flow of water at a maintained and adequate pressure throughout the building. In multi-storey structures, the water tanks are further elevated with stands to provide good water pressure. They are placed on stands to provide this elevation (Friedman [16]).

With the varying sizes of roof tanks, one major function that cuts across is the availability of water at the ready even in the absence of electricity unlike pressurized pumped systems. (Nøgaard \& Nielsen [17]) For roofs that are constructed for fixed roof tanks, they may be either domed or coned. Fixed-roof tank is the least expensive to construct and is generally considered the minimum acceptable equipment for storing liquids. A typical fixed-roof tank consists of a cylindrical steel shell with a cone- or dome-shaped roof that is permanently fixed to the tank shell. Storage tanks are usually fully welded and designed for both liquid and vapor tight (BNH [18]).

Rooftop air conditioning units: In large multi-storey structures, there is the need to make adequate use of pace within the building and as such, there is the need to identify which part of 
the building to store these bulky air conditioning units. There are normally two convenient choices which are either to keep them in the basement or store them on the roofs of the building. Storing them in the basement of the building may not be a bad idea but that means, a room within the building is not usable. Additionally, heat produced by the units if not properly directed out of the building would cause problems in the room (Jamari [19]).

Mounting air conditioning systems on the roofs are the convenient solution to cooling systems within buildings. It is known that air conditioning units take up space and mar the structure's aesthetics. By using the roof tops of multi-storey structures to house the air conditioning units whiles ducts are created within the building to circulate the cool air. Mounting it on the roofs affords a reduced noise level within the building and keeps the units out of the way (Rogers [20]). Roofs of multi-storey structures are converted to store the external air conditioning units and keep them away from sight. These units are connected to vents and air duct to cool the entire structure. At the same time, the noise and vibrations caused by their operation are kept out.

In multi-storey structures, cooling requires larger and bulkier units and as such the only convenient method of storing these units and keep them from taking up space within the structure would be to keep them on the roofs. Keeping these units on the roofs also minimizes the chances of theft and vandalism by users and visitors. With rooftop units, there is adequate space for expansion if there is a need (Pezza [21]).

Frequency antennas and dishes: It is a common sight to find aerials, antennas, masts and satellite dishes mounted on the roofs of buildings. The roofs of these structures are used to accommodate such services. These antennas pick signals and offer clearer services. The roofs of these structures are basically used to store and mount the masts, antennas and aerials. They are kept out of the way of users of the building and are free from interruptions because of the heights they ae placed at. By placing them on the roofs, they offer broader range of getting frequencies and hence offer better services for the building. They are mostly for picking up TV channels, Radio stations and cellphone signals. The roofs of these multi-storey structures offer the adequate and requisite space for accommodating these tall and bulky accessories while keeping them out of the way of users of the buildings. They also provide space for antennas and dishes to be added in the future without compromising the space utilization of the building.

\section{Drainage functional roofs}

These are usually adapted in low-rise multi-storey buildings to provide drainage from storm and rain water to be collected and in most cases used within the building. The primary function of these roofs lies in its ability to adequately and efficiently collect storm water or rainwater. This is done as quickly and as economical as possible to prevent seepage inside the building. In places with high rain climates, the probability of having a seeping roof is so high and as such the roofs of these structures are turned into drainage roofs. Roof drains channel the rain water from roof surfaces into the drainage lines harmless to humans and harmless to buildings. They should be provided wherever rain water can accumulate on the roof and must be safely drained.

In many buildings with the traditional pitched or sloping roofs, rain gutters and pipes are used to move water away from the roofs. However, they are a prime source of dampness found in walls when poorly constructed. With major emphasis being placed on recycling and sustainable living, rainwater is now collected, recycled and used within buildings. It is commonly used to flush WC's, irrigate plants and wash cars. This water is referred to as "grey water" (Emmitt \& Gorse [22]).

In the considering the type of drainage to be used on multistorey structures, thought is given to the construction of the roof. The roofs may be; non-ventilated roof, inverted roof, multi-storey car park, plates in gravel bed, stilted panels, green roof and gravel covered roof. Generally, as a precaution, a sealing agent is used to prevent the rainwater from seeping through the roof. It may be Bitumen or Plastic Roof Sheathing. With the varying types of roof construction one sealing agent may be enough. In other types, two sealing membranes need to be in use to work with the roof drains (ACO [23]). In snow falling regions, roof drains are equipped with heating systems to melt snow and prevent blockage. The snow is melted and collected for use within the building. A thermostat is use to regulate the heater for the roof drain to prevent unnecessary energy consumption.

\section{Structure stabilization roofs}

These roof structures form an integral part of the building. In that, they form a part of the envelope of the building. Such roofs comprise of a structural framework that support the building and becomes a part of the building as a whole. Most a designed to bear the weights of the buildings external shell and to an extent form a part of the buildings major load bearing element. Some such structures are further explained.

World trade centre transportation hub, "The Oculus", New York: This mind boggling structure was designed by Spanish Architect Santiago Calatrava. The Oculus is the center piece for the trade center and is designed to serve as a train station. The Hub is a multi-level building incorporated with a Roof made of Vierendeel Truss. The Vierendeel Truss is not the common form of trusses with diagonal braces. They are made of members rigidly joined together where each member is required to transmit shear, bending and direct stress. The advantages of the rigid frame truss are simplicity of form, simpler details, and hence a cheaper fabrication (Pearson [24]). 
Design of the Hub includes fully integrated, climate-controlled concourses, mezzanines and platforms featuring high performance lighting and elegant finishes. The construction of the mezzanine roof was first done to speed up the completion time specified to be opened to the public. The Oculus is shaped like a back bone. This roof serves as the stabilizer for the structure as the trusses used run through the entire length of the building (World Trade Centre Report [25]).

This Oculus is constructed in memory of the historic 9/11 terrorist attack that claimed about 2,753 people. Santiago's vision for the structure should have been a movable building, "a bird in flight". However due to budget concerns, the idea was scaled down. The roof of the Oculus is constructed with retractable glass panels that would be opened every 9th of September in remembrance of the fallen (Rosenberg [26]). This roof structure indeed represents contemporary models of our architectural times and hence cannot be lumped together with the older classes of roofs.

\section{Kauffman center for the performing arts}

This structure is a pair of two distinct shell-like structures combined to become the Performing Arts Center. It is situated in Kansas and was designed by Sadfie Architects. The exterior is clad in stainless steel and the two venues are connected by a 20 -meterhigh glass-walled atrium that is anchored to the ground by a line of steel cables. Evidently the roof of the structure forms the structural framework of the building with its shell-like design. The glass walls allow daylight into the building and invert the building at night allowing the insides of the building to be viewed from outside (Hursley [27]).

\section{Conclusion}

From the various case studies shown above, it is visible that what is presently being used to classify the roofs of multi-storey structures are not suitable. The roofs of these structures are designed to be used beyond the traditional functions roofs serve and as such they do not conform to the classifications being taught at the various educational levels. It is important to note that what we are taught in the various classrooms impact to a very high degree our direction and views of various topics. In order to advance the thinking skills and influence the way in which students from our tertiary institutions view the construction industry, there is the need to revise the pedagogic structures $[28,29]$.

Students need to be abreast with current trends and move away from the traditional functions and methods of designing roof structures so as to compete on international podia. The architecture of modern times has evolved and with it designs being produced, hence the need to develop the Ghanaian construction industry. The archaic concept of architecture and construction which do not allow for creativity and an expressionist model of architecture is branded outmoded. With the shift towards a technology based system, students must be encouraged to bring out concepts of design that are not time bound. The pedagogy of multi-storey roof designs is not defined by the present classification and it would go a long way to improve the Ghanaian construction industry if these concepts presented in this paper are adhered to. The architecture of Ghana needs to move away from the outdated and outmoded designs and be abreast with international standards. This is only possible by influencing the students in the classrooms and reforming our pedagogic structures in various educational institutions.

\section{References}

1. Alexander BK (2012) Performance Theories in Education. Routledge Taylor Francis Group, New York, USA.

2. Design Buildings Ltd (2017) Multi-Storey Buildings.

3. Barry R (1999) The Construction of Buildings $7^{\text {th }}$ edn. Volume 1 .

4. Urbanik J, Tomaszewicz A (2014) Flat roof - advantage or disadvantage of modern Movement buildings, SAHC $2014-9^{\text {th }}$ International Conference on Structural Analysis of Historical Constructions, Mexico.

5. Chudley R, Greeno R (2007) Construction Technology. $4^{\text {th }}$ edn, pp. 259303.

6. Wells A (2014) Difference Between Pitch and Slope. A J Wells Roofing Contractor.

7. Singart (2018) Art Science Museum, USA.

8. Britannica (2018) Lotus Temple. Encyclopædia Britannica, India.

9. Afful A (2016) Best Practice Examples of Innovation in Sustainable Construction: Lessons for The Ghanaian Construction Industry (Consultant's Perspective)" Knust.

10. The Cultural Landscape Foundation (2016) Kraiser Rooftop Garden.

11. De Dakdokters (2018) Roof Parks. Europe.

12. Marina Bay Sands (2017) Architecture of Marina Bay Sands.

13. Brevoord N (2016) Frankfurt's New Beach. Journal Frankfurt, Germany.

14. Gearson/Overstreet Architects (2003) San Francisco General Hospital Air Medical Access Needs and Feasibility Study Helipad Site Study. Ch $4: 1-27$.

15. Walnut Creek Municipal Code (2017) Helicopters, Heliports and Helistops. Chapter 8.

16. Friedman D (2018) "Rooftop Water Tanks, Cisterns \& Free-Standing Water Storage Towers; Rooftop water tank types, materials and history.

17. Nøgaaard J, Nielsen A (2018) Water supply in Tall Buildings: Roof Tanks vs Pressurized Systems. Grundfos Water Boosting, Whitepaper p. 1-4.

18. BNH (2018) Fixed Roof Tank. India.

19. Jamari N (2011) Air Conditioning for Large Multi-storey Buildings SlideShare.

20. Rogers E (2017) The Best Roof Mounted Air-Conditioners.

21. Pezza T (2017) The Benefits of Rooftop HVAC Systems for Businesses. AAA Heating and Cooling Systems Inc, USA.

22. Emmitt S, Gorse C (2010) Barry's Introduction to Construction of Buildings. $2^{\text {nd }}$ edn, pp. 731.

23. ACO (2018) Gravity Rainwater Drainage ACO-K9-en_Kap06. 
24. Pearson R (1959) Design of Vierendeel Trusses. Masters Theses.

25. World Trade Centre Report (2008) A Roadmap Forward. The Port Authority of NY \& NJ.

26. Rosenberg Z (2015) The Skylight of the World Trade Center Oculus will open every Sept 11. Curbed New York blog, USA
27. Hursley T (2011) Kauffman Centre for the Performing Arts/ Safdie Architect. Arch Daily.

28. Environmental Protection Agency (2017) Using Green Roofs to Reduce Heat Islands, USA.

29. Singart (2018) Art Science Museum, USA.

\section{(c) (1) \\ This work is licensed under Creative Commons Attribution 4.0 License}

To Submit Your Article Click Here:

Submit Article

DOI: 10.32474/TCEIA.2018.01.000117

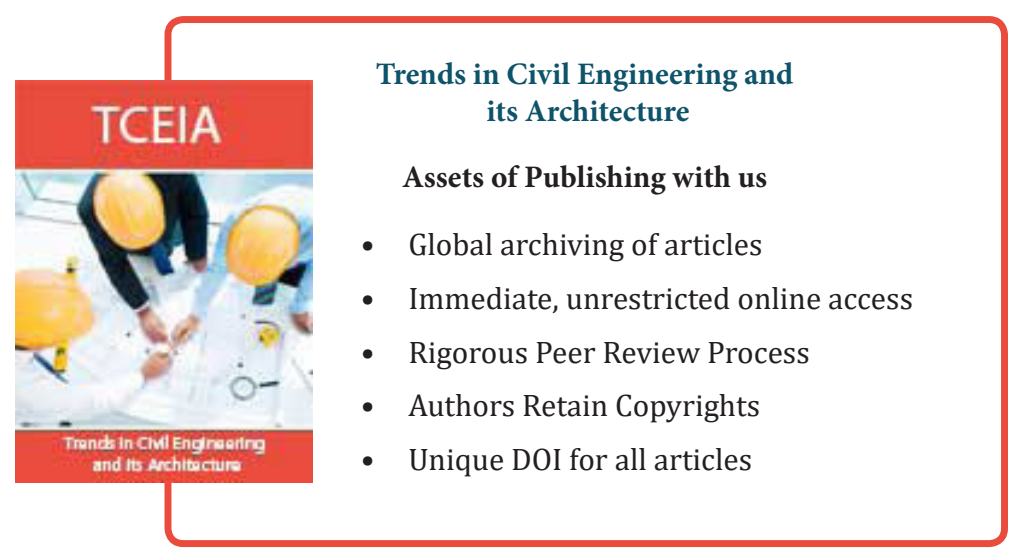

